\title{
JUSTICIA Y DIFERENCIA EN UNA SOCIEDAD GLOBAL COMPLEJA*
}

\author{
Marcelo Neves** \\ Universidad Federal de Pernambuco
}

I

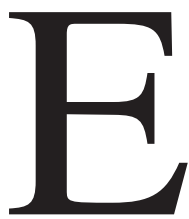

1 título de mi conferencia incluye términos ambiguos en su intensión y vagos en su extensión. Por tanto, para un tratamiento adecuado del tema que se me propuso, es condición previa una precisión semántica de los términos utilizados en el título, evitando así que mi exposición se reduzca a un juego retórico vacío. En otras palabras, es indispensable determinar preliminarmente cómo entiendo el mensaje contenido en el título de la conferencia.

En primer lugar me gustaría esclarecer que dentro del contexto del título de mi conferencia, comprendo el término «justicia» como referencia lingüística a un modelo normativo de evaluación de la conducta en interferencia intersubjetiva o de evaluación de decisiones vinculantes, y no como una referencia lingüística a un órgano o institución del Estado de Derecho, pese a que pueda observarse que tal órgano o tal institución tiene, supuestamente, el papel de velar por la aplicación práctica de ese modelo. Pero esta comprensión semántica de la palabra «justicia», evidentemente, hace aún más complicada la determinación temática de la misma, con lo que se requiere un esfuerzo sobremanera mayor en la especificación del sentido del vocablo.

También cabe advertir que no trataré la relación entre justicia y diferencia en los términos del debate principalmente norteamericano entre liberalismo y comunitarismo ${ }^{1}$, que ya presenta fuertes signos de desgaste por sus

\footnotetext{
* El presente artículo es una versión revisada de la exposición presentada en la XVII Conferencia Nacional de Abogados, realizada en Río de Janeiro, del 29 de agosto al 2 de septiembre de 1999.

** Profesor Titular de la Facultad de Derecho de Recife - Universidad Federal de Pernambuco; actualmente, Profesor Visitante del Departamento de Ciencias Sociales de la Universidad de Francfort (Main).

${ }^{1}$ Ese debate ganó impulso y unos contornos más precisos a partir de la crítica comunitarista de SANDEL (1982) al modelo de justicia liberal concebido por RAWLS (1990 [1972]). Con
} 
formas simplificadoras y recepciones acríticas. La contraposición radical entre justicia universal, referida al individualismo moral, y valores diferentes, referidos al comunitarismo ético, en la cual se adentró ese debate, ${ }^{2}$ volvió a éste poco fructífero para un tratamiento de la relación dinámica entre justicia y diferencia en una sociedad global compleja. Mi argumentación en la exposición que sigue se articula entorno a la tesis de que el universalismo de la justicia implica, asimismo, un tratamiento adecuado de la relatividad y de la diferencia de valores. La justicia no puede reducirse a un universalismo moral individualista, no es un atributo exclusivo del liberalismo. La justicia se afirma en cuanto es sensible a la diferencia, comprendiendo ésta aquí no sólo como diferencia de valores colectivos o incluso individuales, sino también como diferencia de esferas de comunicación.

La justicia puede comprenderse, desde el punto de vista de la teoría sistémica, como una complejidad adecuada del sistema jurídico (desde una perspectiva externa) o como una consistencia de sus decisiones (desde una perspectiva interna) (LuHMANN, 1988: 26 s., 1981: 388 ss.). De acuerdo con esa formulación, la justicia se concibe como fórmula-de-contingencia del Derecho, en referencia a la «diferencia entre indeterminabilidad y determinabilidad» (LuHMANN, 1993: 220). Pero tal comprensión sistémica cae en el vacío si la «justicia en el sentido de una complejidad adecuada del decidir consistente» (id., ibid.: 225), que se presenta como una fórmula-de-contingencia del sistema jurídico, no está relacionada con el principio de igualdad, que presupone la forma-diferencia «igual/desigual» y cuyo objetivo es el tratamiento igual de los iguales y desigual de los desiguales (id., ibid.: 110 ss. e 223 ss.). Así pues, partiendo de que el Derecho se presenta como «mecanismo del tratamiento igual/desigual» (TEUBNER, 1996a: 211), conceptuaré la justicia en la presente conferencia como el(los) modelos(s) normativos(s) de evaluación del tratamiento consistente y adecuadamente complejo de la diferencia «igual/desigual» que se contruye(n) con pretensiones de universalidad en el plano de la observación de segundo orden del sistema jurídico.

Por diferencia no comprendo aquí toda forma de diversidad natural o cultural, sino únicamente aquellas diversidades que puedan tener una relevancia normativa para el Derecho, especialmente para el tratamiento «igual/desigual». Con esa acepción es relevante sobre todo la heterogenei-

la etiqueta de «comunitarismo» se vino entonces a hacer referencia a los autores más divergentes, entre los que, amén de Sandel, destacan Charles Taylor, Alasdair MacIntyre y Michael Walzer; con la etiqueta de «liberalismo», también muy diversos autores entre los que además de Rawls sobresalen Ronald Dworkin, Thomas Nagel y Bruce Ackerman (cf. HonNETH, 1995: 7).

${ }^{2}$ El propio TAYLOR (1991) reflexiona acerca de la tendencia simplificadora de ese debate. 
dad de valores, intereses y discursos que caracteriza la sociedad contemporánea. Defino valores como las preferencias individuales o colectivas relacionadas con el (¿buen?) modo de vida (valores-preferencia) o como las evidencias (formas indiscutibles de actuar y de vivenciar) que son constitutivas de la formación de la identidad de individuos y grupos (valores-identidad). Concibo intereses como las formas en que las relaciones entre medios y fines se manifiestan en el comportamiento y en las comunicaciones de individuos y grupos. Y entiendo por discursos los diversos juegos de lenguaje en que los diferentes valores e intereses circulan de una manera conflictiva.

Cuando me refiero a «sociedad global» no quiero recurrir aquí simplemente a la etiqueta de «globalización», pues su uso abusivamente ideológico, por una parte, y su imprecisión omnipresente en los diversos campos de la producción cultural, por otra, la convierten a menudo en la palabra clave de una retórica inconsistente. Con la expresión «sociedad global» me referiré en lo sucesivo a «sociedad mundial» como aquella que se desarrolla, paulatinamente, a partir del siglo XVI (cf. LUHMANN, 1997: 148 o LUHMANN / De GioRGI, 1992: 47). La llamada «globalización» debe entenderse como una intensificación de esa sociedad, que se construye, primariamente, a partir de la economía, la técnica, la ciencia y los medios de comunicación de masas: las relaciones sociales y las comunicaciones se intensifican más allá de las fronteras entre Estados como organizaciones político-jurídicas territoriales y de las fronteras culturales entre «naciones» y etnias. La globalización también puede verse como una explicación, en las últimas décadas, de características de la sociedad mundial que ya se encontraban latentes anteriormente (cf. BRUNKHORST, 1999: 374). Y, en cuanto problema que emerge dentro de la sociedad mundial, toma relevancia la globalización económica, que supone un expansionismo del sistema económico a nivel mundial con efectos destructivos para el resto de las diversas esferas sociales, en especial para la política y el derecho. No obstante, los teóricos de la globalización parten de un concepto de sociedad basada en el Estado Nacional (cf., por ex., GIDDENS, 1991: esp. 13) o de una concepción cultural de sociedad (cf., por ex., Robertson, 1992). Antes bien, cabe hablar de una sociedad mundial (moderna) en que las comunicaciones se reproducen globalmente $\mathrm{y}$, por tanto, el horizonte del actuar y del vivenciar va más allá de todas las fronteras regionales. Sin embargo, en el ámbito político-jurídico, esa sociedad está diferenciada segmentariamente en Estados en cuanto organizaciones territorialmente delimitadas, e incluye en sí las más diversas culturas.

Por último, al definirse la sociedad mundial como una sociedad «compleja», se emplea aquí este adjetivo en el sentido sistémico del término «complejidad», que se refiere a la presencia permanente de más posibilida- 
des (alternativas) que las susceptibles de actualizarse (LuHMANN, 1987a: 31, 1989: 4 s.). Con esa acepción se afirma que la sociedad mundial (moderna) es supercompleja porque las alternativas posibles de conductas, comunicaciones, relaciones y hechos sociales son mucho mayores que aquellas que se pueden realizar efectivamente en una situación concreta. La complejidad implica, a su vez, contingencia. Ésta supone que de entre las diversas posibilidades puede actualizarse una que no se esperaba, causando un «peligro de frustración y la necesidad de asumir riesgos» (LuHMANN, 1987a: 31)3. La supercomplejidad y la supercontingencia de la sociedad global de hoy acarrean el aumento de necesidad de selección (LuHMann, 1987b: 47), pero exigen, no obstante, mecanismos selectivos que no excluyan definitiva y absolutamente ninguna de las posibilidades. La reducción selectiva de la complejidad conduce al aumento de complejidad, esto es, los mecanismos selectivos se destinan a transformar la complejidad desestructurada en complejidad estructurada, sin ignorar, por tanto, la heterogeneidad de valores, intereses y discursos, así como la pluralidad de sistemas existentes en la sociedad.

Hechas estas observaciones relativas a la delimitación semántica del título de la presente conferencia, pretendo abordar a continuación primeramente el concepto de justicia como modelo normativo del tratamiento igual/desigual en términos consistente y adecuadamente complejos, procediendo a un análisis del principio de igualdad, en el que consideraré que éste presupone heterogeneidad social y compatibilizarse con las «discriminaciones inversas» (II). Basándome en esa concepción de la justicia como igualdad, procuraré demostrar cómo el universalismo a ella inherente se concilia con la diversidad de valores de la sociedad global contemporánea (III). A continuación definiré la justicia como igualdad compleja, considerando su variación conforme al juego del lenguaje (discurso) o la esfera de comunicaciones (sistema) a que se refiere el tratamiento igual/desigual (IV). Acto seguido, trataré del Estado democrático de derecho como modelo procedimental más adecuado para la realización de la justicia en la sociedad global de hoy (V). En las consideraciones finales, discutiré acerca del problema de la pérdida de significado del Estado democrático de derecho en virtud, por un lado, de la intolerancia étnica y del fundamentalismo religioso, incompatibles con la diversidad de valores, y, por otro, del expansionismo de la economía con efectos destructivos referidos al derecho y

\footnotetext{
${ }^{3}$ La contingencia puede verse como una dimensión cualitativa de la complejidad. En consonancia con ello, Edgard Morin resalta (1990: 48 s.): «Pero la complejidad no abarca únicamente las cantidades de unidades e interacciones que desafían nuestras posibilidades de cálculo; también abarca las incertidumbres, indeterminaciones, fenómenos aleatorios. La complejidad, en cierto sentido, tiene siempre que ver con el riesgo».
} 
la política, hecho que ha conducido a una ampliación de formas de «exclusión» y desigualdad social, esto es, a una injusticia estructural globalizada; en ese contexto, haré una breve referencia a la viabilidad práctica de la construcción de instituciones jurídicas y políticas globales que pudiesen desempeñar el papel de llevar a cabo la justicia en el lugar del supuestamente ineficiente Estado democrático de derecho (VI).

\section{II}

Al definirse la justicia como (norma de la) igualdad, se impone una comprensión precisa del principio de isonomía, a fin de evitar así una retórica ambigua y vaga, tan común cuando se discute acerca de tal principio.

Inicialmente, debe desecharse toda y cualquier concepción de que se trata de una «igualdad de hecho» en el Estado de derecho. El principio de la igualdad surge exactamente como forma de neutralizar las desigualdades en el ámbito del ejercicio de los derechos. Ese sentido es el empleado al hablar de «igualdad de derecho» $»^{4}$. No obstante, para evitar ilusiones por un lado y, por otro, críticas ideológicas fundadas en la sobrecarga del principio, debe añadirse que el objetivo de éste no es la igualdad en el contenido del derecho y el poder de los individuos y grupos. El principio se refiere más bien al tratamiento isonómico que se obtiene mediante la integración o el acceso igualitario a las instituciones y a los procedimientos jurídicos.

Otro equívoco que ha de ser advertido preliminarmente es el relativo a la confusión entre igualdad jurídica y homogeneidad de la sociedad. Esa confusión se relaciona con una postura simplificadora en cuanto a la caracterización de la sociedad moderna y de la democracia. Al contrario, la complejidad y la heterogeneidad social son presupuestos para la emergencia y concretización del principio jurídico de igualdad. La «homogeneidad estratificada» pre-moderna es incompatible con el principio de igualdad. Es la diversidad de valores, intereses, creencias y etnias en el mismo espacio social y político la que hace posible la implantación de la igualdad. Frente a las diferencias, se puede asumir un modelo autocrático, ya sea éste autori-

\footnotetext{
${ }^{4}$ Cf., por ej., JouvenEL, 1976: 134-44 (trad. bras.: 1978: 160-171), criticando la frase con la cual inicia un clásico de la literatura política del siglo XIX, De la Démocratie en Amérique: «Entre las novedades que llamaron mi atención durante mi estancia en Estados Unidos, no hubo ninguna que me impresionase tanto como la igualdad de condiciones» (ToCQUEVILLE, 1986: 49). Al contrario, JouvENEL sostiene (1976: 135-37 - trad. bras.: 1978: 162 s.), apelando a Sieyès, que no se trata de una «igualdad de medios», sino de una «igualdad jurídica» y que en ese sentido no habría diferencias entre la igualdad francesa y la americana. En nuestro ámbito, distinguiendo entre la isonomía (presupuesto de la aplicación normativa concreta) y las llamadas «libertades materiales» (objetivo político-jurídico referente a la igualdad de condiciones sociales), COMPARATO advierte (1993: 77 s.): «En consecuencia, no se ha de pretender eliminar u ocultar las desigualdades sociales de hecho entre los hombres, como la aplicación de la isonomía».
} 
tario o totalitario, ignorando y reprimiendo la heterogeneidad y pluralidad de la sociedad, o reconocer e incorporar sin privilegios las diferencias. En este sentido, el principio de igualdad sólo se lleva acabo en cuanto posibilita el respeto recíproco y simétrico a las diferencias.

Pese al presupuesto de que el principio de igualdad no tiene la pretensión de establcer una igualdad de hecho en la sociedad, y mucho menos la homogeneidad social, y que supone por el contrario la desigualdad fáctica y la heterogeneidad de valores e intereses, no dejan aún así de surgir dificultades en la delimitación semántica del mismo. El carácter problemático del principio resulta de que sólo puede ser formulado si incorpora la desigualdad como uno de sus polos. En otras palabras, el principio de igualdad se presenta inicialmente por medio de la diferencia entre igual y desigual. No nos restringimos aquí, sin considerar las diferencias de contextos históricos, a retomar la formulación aristotélica de que la igualdad consiste en tratar igualmente a los iguales y desigualmente a los desiguales 5 . En el mundo griego ese modelo implicaba que se justificase incluso la esclavitud. Es innegable, sin embargo, que la formulación clásica del principio de igualdad es susceptible de una relectura o reconstrucción que lo haga compatible con las exigencias de la sociedad contemporánea.

Así es como, reinterpretando el «principio de igualdad» desde una perspectiva sistémica, Luhmann define la igualdad como un concepto formal (una diferencia), que depende de la existencia de otra vertiente, la desigualdad: «La igualdad sin desigualdad no tiene sentido - y viceversa. Si lo igual debe ser tratado igualmente, lo desigual tiene que ser tratado como desigual. [...] Si se renuncia al concepto normativo de igualdad, se llega a la regla aristotélica de tratar igualmente lo igual y desigualmente lo desigual. Se trata, por tanto, de un esquema de observación que sugiere el desarrollo de normas y preferencias, pero que en sí no fija, en última instancia, la preferencia por la igualdad» (LuHMANN, 1993: 111). Dentro de esa orientación la desigualdad es, en primer lugar, una forma que establece una diferencia, «igual/desigual». Y, en ese sentido, es adaptable a los más diferentes tipos sociales, aun incluso las sociedades estratificadas (id., ibid.: 112). Sólo cuando la igualdad se transforma de una forma en una norma es cuando se puede comprender el papel específico del principio de la igualdad en el derecho de la sociedad moderna. Luhmann, considerando que el papel del principio formal de la igualdad es únicamente describir la autopoiesis del

${ }^{5}$ ARISTÓTELES no desconocía el carácter problemático de su formulación: «Si ellas [las personas] no son iguales, no tendrán lo que es igual; pero eso es origen de disputas y quejas o cuando los iguales tienen y reciben partes desiguales, o cuando los desiguales, partes iguales» (1941: 1006 [1131a 20-25]). 
sistema, destaca que el salto lógico reside en la interpretación de la forma como norma (id., ibid. $)^{6}$. De ese modo, la paradoja de la forma se convertiría en la «asimetría de una regla aplicable» (id., ibid.). De acuerdo con el principio normativo de igualdad, el tratamiento igual sería la regla, cuya excepción sería el tratamiento desigual (id., ibid.: 111 s.).

Sin embargo, dentro de la concepción sistémica luhmanniana el principio de la igualdad, en su dimensión jurídica, exige específicamente que se traten los casos igualmente. En su utilización política exige que se trate a los hombres igualmente (LUHMANN, 1993: 113). Así pues, Luhmann reduce el principio jurídico de la igualdad a la exigencia de la regularidad de la aplicación normativa, que como positivación del derecho en la modernidad significa el principio de legalidad. De ello no se desprende que ignore que «el mandamiento constitucional de la igualdad, en cuanto norma jurídica, conduce al hecho de que la igualdad política se interprete jurídicamente como igualdad/desigualdad de casos» (id., ibid.). En el lenguaje kelseniano, el principio de igualdad en su dimensión puramente jurídica implicaría la igualdad ante la ley, mientras que el principio político de igualdad como contenido de precepto constitucional significaría la igualdad en la ley (cf. KELSEN, 1960: 146 e 396). Y cuando se discute sobre el principio constitucional de isonomía como expresión de la justicia en el Estado democrático de derecho, es la igualdad en la ley la que está en entredicho. El tema del debate es en primer lugar la integración igualitaria de los hombres (como personas) en el ordenamiento jurídico; sólo secundariamente, el tratamiento igual de casos y situaciones jurídicas.

El principio de igualdad, mientras tanto, no se restringe a la integración sistémica igualitaria. La noción de integración procedimental igualitaria puede leerse desde dos perspectivas diversas e inseparables. Desde el punto de vista sistémico, la cuestión se refiere a la neutralización de las desigualdades fácticas en la consideración jurídica de individuos y grupos. Pero, por otra parte, es imprescindible que en la esfera pública pluralista se haya desarrollado la idea de que las diferencias sean recíprocas y simétricamente respetadas. Eso exige que los procedimientos constitucionales se presenten como sensibles a la convivencia de lo diferente y, de esa modo, les posibiliten un tratamiento jurídico igualitario. Es desde esa perspectiva como cabe una relectura de la concepción de Dworkin del derecho «fundamental» a un igual respeto y consideración (DWORKIN, 1991a: 180 ss. e 272 ss. $)^{7}$. Éste consiste en el derecho a «ser tratado como un igual» [treatment as an equal], y se disqtingue del derecho al «tratamiento igual» [equal

\footnotetext{
${ }^{6}$ Sobre la igualdad como forma y como norma, cf. análogamente LUHMANN, 1991.

${ }^{7}$ DwORKIN lo concibe como «derecho natural» (cf. , por ej., 1991a: 182).
} 
treatment], que se refiere a una distribución igual de oportunidades, recursos o cometidos y sería «derivado» (id., ibid.: 227). Evidentemente, la «fundamentalidad» del derecho a un igual respeto y consideración exige una esfera pública pluralista donde se asiente el respeto recíproco y simétrico a las diferencias. Así pues, este derecho es un presupuesto para que los sistemas político y jurídico puedan institucionalizar el derecho a un tratamiento igual. Es decir, el primero se construye a partir de la esfera pública pluralista, el segundo se presenta como una respuesta sistémica a las exigencias de integración jurídica igualitaria. Aquél, sin embargo, se diluye en caso de no estar sistémicamente asegurado el derecho a un tratamiento igual. Si los sistemas político y jurídico proceden a una distribución desigual de oportunidades y cometidos (p. ej. si establece el voto desigual o privilegios corporativos), no cabe hablar ya de derecho a un igual respeto y consideración asentado en una esfera pública pluralista. Por tanto, en vez de relación de fundamentalidad y derivación, se puede afirmar que se trata de la presuposición recíproca de las dos perspectivas desde las cuales el principio de igualdad puede observarse: la perspectiva interna y sistémica, referente al tratamiento jurídico igual, que implica la neutralización de las desigualdades presentes en el medio ambiente; la perspectiva externa de la esfera pública pluralista, relativa al derecho a ser tratado como un igual o derecho a un igual respeto y consideración.

Uno de los problemas más delicados afrontados cuando se enfoca el principio de igualdad se refiere a la posibilidad y los límites de regulaciones jurídicas y programas políticos destinados a establecer ventajas en favor de grupos sociales discriminados. Con respecto a la experiencia norteamericana, Dworkin considera favorablemente la «acción afirmativa» en beneficio de las minorías étnicas discriminadas, argumentando que la Décimocuarta Enmienda a la Constitución de los Estados Unidos de América, al estipular que «ningún Estado podrá [...] negar a cualquier persona bajo su jurisdicción la igual protección de las leyes, está asegurando en realidad el derecho fundamental a ser tratado como un igual» (DwORKIN, 1991a: 223239, esp. 227 ss.). Basándose en este argumento concluye que el programa de discriminaciones «inversas», también denominadas afirmativas o positivas, tales como las que favorecen la admisión de minorias raciales socialmente discriminadas en sentido negativo, «se justifica si sirve como política adecuada que respete el derecho de todos los miembros de la comunidad a ser tratados como iguales, pero no en caso contrario» (id., ibid.: 239). Dworkin reconoce que los efectos prácticos de las mismas pueden ser contrarios a los que defienden sus partidarios. Esa cuestión empírica sigue discutiéndose aún hoy en los Estados Unidos de América, con una intensificación de las tendencias opuestas. «Sin embargo, no debemos corromper el 
debate»-así cierra Dworkin su ensayo Reverse Discrimination- «suponiendo que esos programas son injustos, incluso aunque funcionen. Debemos tener cuidado para no usar la Cláusula de Igual Protección para privarnos de la igualdad» (id., ibid.). ${ }^{8}$

La compatibilidad de las discriminaciones inversas como el principio de igualdad puede concebirse de una modo más inclusivo. Este principio normativo presupone la forma-diferencia «igual/desigual», de modo que puede afrontar las disimilitudes reales entre casos, situaciones y personas, en especial aquellas que impliquen la negación de derechos básicos a individuos y grupos. En este sentido es destacable, a nivel nacional, la contribución de Celso Antônio BANDEIRA DE Mello (1993) en cuanto al contenido jurídico del principio de igualdad. En un enfoque jurídico-positivo, pero con implicaciones para la teoría general del derecho y de la Constitución, Bandeira de Mello subraya que el principio constitucional de isonomía conlleva discriminaciones legales de personas, cosas, hechos y situaciones. Discute, entonces, cuándo las dicriminaciones se justifican sin que se desvirtúe el principio vector. Y menciona tres exigencias: la presencia de rasgos diferenciales en las personas, cosas, situaciones o hechos (1993: esp. 23-35); «correlación lógica entre el factor de discriminación y la disparidad llevada a cabo» (id., ibid.: 36-40); consonancia de la discriminación con los intereses y valores protegidos en la Constitución» (id., ibid.: 41-43). Pese a que Bandeira de Mello no haya afrontado el problema de la discriminación positiva de grupos socialmente desfavorecidos, nos parece que su línea de razonamiento se orienta perfectamente hacia la compatibilización de tal especie de discriminación con el principio constitucional de isonomía, apartándose de ciertos prejuicios derivados de interpretaciones literales del Art. 5., caput, de la Constitución Federal.

Y es exactamente la presencia de discriminación social negativa, que implica incluso obstáculos reales al ejercicio de derechos, la que justifica la discriminación jurídica afirmativa en favor de determinados grupos e individuos. En ese caso se da una perfecta correlación lógica entre el factor de discriminación y la disparidad que, eventualmente, se lleva a cabo. La introducción de ventajas competitivas en beneficio de grupos desfavorecidos podrá fundamentarse constitucionalmente como la institucionalización de medios jurídico-políticos que se destinan a posibilitar la integración igualitaria de todos en el Estado y en la sociedad en general. Evidentemente, es plausible el argumento dworkiniano de que se trata de favorecer la realización social del derecho a ser tratado con igual respeto y consideración, in-

\footnotetext{
${ }^{8}$ Cf. Dworkin, 1991b: 395-97, con una posición más cauta en cuanto a su actitud anterior con respecto a la «acción afirmativa».
} 
crementando la igualdad en la sociedad. Pero se puede formular el principio de igualdad, en lo que respecta en particular al problema de los grupos e individuos discriminados, del siguiente modo: cuanto más se sedimenta históricamente y se hace efectiva la discriminación social negativa contra determinados grupos, principalmente en los supuestos en que ésta implica obstáculos relevantes al ejercicio de derechos, tanto más se justifica la discriminación jurídica afirmativa en favor de sus miembros, siempre y cuando ésta se oriente en el sentido de la integración igualitaria de todos en los diversos procedimientos del Estado de Derecho. De ese modo, el principio constitucional de igualdad resulta sensible a las diferencias presentes en la realidad social e inseparable del principio de proporcionalidad. Por último, se puede concluir que pese a tratarse de una paradoja, pues la presencia de sectores discriminados conlleva límites en la construcción de una esfera pública pluralista, las discriminaciones legales afirmativas se justifican con arreglo al principio de igualdad en cuanto reaccionan proporcionalmente a las discriminaciones sociales negativas contra los miembros de esos grupos y desde el momento en que pretenden la integración jurídica igualitaria de todos en el Estado y en la sociedad en general.

\section{III}

La justicia como igualdad aspira a la universalidad. Ésta no se entiende aquí desde una perspectiva histórica. Antes bien, el universalismo de la justicia se relaciona con una conquista de la modernidad, cuyo objetivo es el acceso generalizado de individuos (como personas) y grupos al derecho. Ello exige, ciertamente, la neutralización de desigualdades sociales, en especial de aquéllas de naturaleza económica y política, en el plano del ejercicio de derechos establecidos como fundamentales. Y cuando esas desigualdades en sí mismas representan obstáculos para el ejercicio de derechos básicos y favorecen el privilegio jurídico de minorías, se justifican los mecanismos compensatorios que se expresan en los derechos sociales e, incluso, las discriminaciones inversas en forma de programas que crean ventajas competitivas. Mientras, sigue ahí la cuestión que viene planteando el comunitarismo radical, así como el multiculturalismo extremo: ¿no sería el universalismo de la justicia como igualdad una ideología que esconde las diferencias fundamentales entre grupos étnicos y culturales, cada uno de ellos con sus propios valores? Y, en ese sentido, ¿no se impone una subordinación de la justicia a los criterios valorativos de cada grupo particular? Como respuesta a esas cuestiones, se desarrolla una crítica al universalismo abstracto de la concepción liberal de justicia y se extiende un relativismo particularista en la legitimación del derecho y de la política. Por decirlo así, 
los valores de cada grupo constituyen, desde esa perspectiva, el modelo mismo de justificación última del respectivo orden jurídico-político.

Al modelo comunitarista se puede contraponer el argumento tradicional de que una elevación de los valores grupales, ya sean los de preferencia o los de identidad, a criterio de legitimación última del orden político-jurídico impide cualquier posibilidad de crítica consecuente a regímenes totalitarios de base étnica o nacionalista. Por añadidura, cabe destacar que la concepción comunitarista, en la sociedad global supercompleja y culturalmente heterogénea de hoy, se muestra profundamente inadecuada. No sólo entre las diversas fronteras estatales se observa una fuerte diversidad de valores y etnias, sino que también en el ámbito del territorio de cada Estado se hallan presentes los más diversos valores grupales, que por lo general se encuentran en relación de conflicto. A partir de este dato innegable, me parece equivocada una fundamentación ética (referente a la autorrealización del grupo o a sus preferencias) o étnica (referente a la identidad del grupo) de los sistemas político y jurídico, ya sean éstos estatales o supraestatales, y sobre todo de la sociedad misma. Teniendo en cuenta la diversidad cultural y étnica de la sociedad global de hoy, incluso dentro de los respectivos territorios estatales, la insistencia en un modelo comunitarista de orden político-jurídico impide un análisis consistente y un tratamiento adecuado de los problemas estructurales de la sociedad global de hoy, vinculados en el plano de la práctica política a formas de nacionalismos étnicos y fundamentalismos religiosos que son incompatibles con el Estado democrático de derecho.

Mientras, el multiculturalismo extremo, al ensalzar la diversidad de valores y etnias que caracterizan la sociedad de hoy en día, tampoco es capaz de ofrecer ningún modelo consecuente para el tratamiento jurídico-político de las diferencias culturales. Partiendo empíricamente del hecho de que diversas culturas están presentes en la sociedad, sostiene desde un punto de vista normativo que deben respetarse las diversas identidades grupales, de tal modo que cualquier restricción a la identidad de un grupo étnico o cultural se concibe como injustificable. Un hecho que el multiculturalismo extremo no toma en consideración suficiente y adecuadamente es que las diversas identidades grupales están a menudo en conflicto, muchas veces de forma destructiva para el Estado y la sociedad. Ello exige una relectura del multiculturalismo empírico en el plano normativo de la construcción del orden jurídico-político. Criticando el multiculturalismo radical observa con razón Alain TOURAINE que «no hay sociedad multicultural posible sin recurrir a un principio universalista que permita la comunicación entre los individuos y los grupos social y culturalmente diferentes» (1997: 206). En consonancia con ello, destaca que «es necesario rechazar con idéntica fuerza 
una concepción jacobina de la ciudadanía y un multiculturalismo extremo que rechaza todas las formas de ciudadanía» (1994: 99). El hecho es que sin la universalidad de la ciudadanía, esto es, sin la inclusión generalizada de individuos y grupos en el sistema jurídico-político, las diferencias étnicas y culturales degeneran en conflictos destructivos entre los diversos grupos. Es decir, el hecho empírico del multiculturalismo mismo exige una concepción de la justicia y de la ciudadanía que sea universalmente sensible a la diferencia. El universalismo de la justicia como igualdad, que presupone el universalismo de la ciudadanía como inclusión generalizada en el sistema jurídico-político, se presenta entonces como un universalismo relativo que exige el respeto recíproco a las diferencias.

No se trata, por tanto, de un relativismo ético en el sentido tradicional de esta expresión. Desde la perspectiva relativista cualquier patrón de valores se legitima en su respectivo contexto social o incluso personal. Pero tal perspectiva en una sociedad compleja y culturalmente heterogénea no puede presentar modelo normativo alguno en el sentido de la construcción de un orden jurídico-político estable y justo. Esta perspectiva conduce al mismo problema del multiculturalismo extremo, en la medida en que no es capaz de ofrecer patrón normativo alguno para la mediación o tratamiento de los permanentes conflictos entre las diversas identidades grupales que se encuentran presentes en la sociedad contemporánea. El problema normativo que se plantea en el contexto de la sociedad global de hoy, donde la intensa ola migratoria incrementa cada vez más la plurietnicidad y el pluriculturalismo en el interior mismo de los territorios de los respectivos Estados, es cómo afrontar constructivamente las diferencias étnicas y culturales, impidiendo la degeneración del conflicto entre los diversos grupos y combatiendo los fundamentalismos. Lo que se requiere, por tanto, es el acceso igualitario de las diversas preferencias valorativas e identidades étnicas a los procedimientos jurídico-políticos. Ello implica que ninguna de ellas pueda tener pretensiones de prevalecer absolutamente sobre las demás excluyéndolas. La primacía de los valores de un determinado grupo en un determinado procedimiento (electoral, legislativo, administrativo o jurisdiccional) del Estado democrático de derecho se justifica únicamente en cuanto es relativa, es decir, desde el momento en que los procedimientos permanecen abiertos a los valores del resto de grupos, que podrán prevalecer en otra eventualidad procedimental. Esto significa que la justicia como igualdad exige un orden jurídico-político que tiene como base y como exigencia el respeto recíproco a las diferencias étnicas de grupos y de individuos. La intolerancia étnica, que reacciona destructivamente frente al hecho de la plurietnicidad, y el fundamentalismo religioso, cuyo objetivo es la imposición de una homogeneidad étnica, son incompatibles con la complejidad y hete- 
rogeneidad de la sociedad global de hoy e injustificables desde el punto de vista del orden jurídico-político. En este sentido, el reconocimiento absoluto de la diferencia, que subyace al relativismo ético y a su expresión práctica de hoy, el multiculturalismo extremo, es irreconciliable con la justicia como igualdad, que exige el respeto recíproco a las diferencias y la comunicación -de hecho, intensamente discrepante y conflictiva- entre los diversos grupos en el ámbito de una esfera pública pluralista. De ese modo se relativiza el reconocimiento de la diferencia, y así valores éticos e identidades étnicas que rechazan o niegan la heterogeneidad cultural de la sociedad y excluyen pues a otras etnias y culturas, son incompatibles con el universalismo de la justicia y de la ciudadanía y, en consecuencia, deben sufrir restricciones por parte del orden jurídico-político. El universalismo de la justicia se afirma, respecto de las diferencias étnicas y valorativas, como una igualdad de tratamiento jurídico de los diferentes grupos y una igualdad de acceso de los mismos a los procedimientos jurídico-políticos, exluyendo cualquier discriminación o privilegio. Pero la justicia como igualdad sólo está asegurada si se imponen restricciones efectivas a los grupos que basándose en una identidad étnica o en valores ético-religiosos pretendan destruir el propio orden normativo, el cual fundamenta el universalismo inherente a la igualdad de tratamiento y de acceso jurídico-político de los diferentes grupos. El universalismo de la diferencia sólo se afirma, por tanto, como universalismo de la igualdad.

\section{IV}

El problema de la relación entre justicia y diferencia en la sociedad global de hoy no se restringe, mientras, a la cuestión de la relación entre la igualdad y la diversidad de culturas y etnias. Aunque no se deba descuidar esta cuestión, pues los conflictos étnicos han alcanzado recientemente una dimensión que no se había considerado debidamente en las ciencias sociales de las últimas décadas (cf. LuHMANN, 1998: 372), gana cada vez más en significado el problema de la relación de la igualdad con las diversas esferas de comunicación. Michael WALzer (1983) se aproximó a esta temática cuando trató de las «esferas de justicia», refiriéndose en ese contexto a la «igualdad compleja» (1983: 3 ss.) definida en los siguientes términos: «Lo que la norma de la igualdad compleja exige es una sociedad donde a aquellos hombres que tienen más dinero, más poder o más conocimientos técnicos (y esos hombres siempre existirán) se les impida, sólo por ese hecho mismo, tomar posesión de cualquier otro bien social» (1998: 12). La concepción de Walzer, como se desprende ya de ese fragmento, permanece en el plano de la justicia distributiva, teniendo como foco únicamente las «cosas, los objetos de distribución» (WALzER, 1994: x). Primeramente cabe ad- 
vertir que la justicia como modelo normativo del tratamiento igual/desigual, de acuerdo con la argumentación ya presentada en el apartado II, no se refiere únicamente a objetos distribuibles, sino también a casos, situaciones y, sobre todo, a personas. Por tanto, desde esa perspectiva, la justicia como «igualdad compleja» no se reduce a la diversidad de los criterios de distribución de bienes según esferas diferenciadas de objetos, sino que más bien está relacionada a modo inclusivo con la variación del modelo normativo de tratamiento igual/desigual en las diversas esferas de comunicación. En este sentido, según el juego de lenguaje (discurso) o, de un modo más simple, el sistema social (economía, política, familia, educación, ciencia, arte, religión, etc.), debe variar el modelo de tratamiento igual/desigual. Teniendo en cuenta que la complejidad social implica la diferenciación de la sociedad en diversas esferas autónomas de comunicación y, correspondientemente, en distintos juegos de lenguaje, la justicia como igualdad se diferencia para responder adecuadamente a tal complejidad.

La justicia como igualdad compleja presupone y exige, en primer lugar, que los códigos y programas de una esfera de comunicación no se impongan directamente a otra esfera de comunicación. Por ejemplo, es un imperativo de la justicia en una sociedad compleja que «el punto central de la racionalidad interna de un sector social autónomo, como la investigación, la sanidad o la educación, no debe ser sustituido por la racionalidad económica» (TeubNer, 1998: 21 s.). En general, puede decirse que la racionalidad de un campo de comunicación no debe reducirse a la de otro así como afirmar que los códigos y criterios de una esfera social autónoma no deben ser saboteados por las exigencias de otra. En este sentido, Luhmann destaca igualmente que «ahora, los saboteos de código se convierten en el problema moral - algo así como la corrupción en la política y en el derecho o el dopaje en el deporte o la compra de amor o el falseamiento con datos de la investigación empírica» (LuHMANN, 1997: 1043). En lo que a los diversos juegos de lenguaje respecta, se impone una justicia discursiva como «justicia respecto de lo heterogéneo» (Welsch, 1991: 176). Desde esta perspectiva, justicia significa «la relación entre identidad y alteridad discursiva, no desde la perspectiva de un tercero, sin embargo, sino desde la perspectiva singular del respectivo discurso en relación con otros mundos discursivos» (Teubner, 1996a: 218). En suma, la justicia como igualdad compleja presupone y exige el reconocimiento de la pluralidad discursiva y la complejidad sistémica de la sociedad global de hoy, que implica el respeto a la autonomía de las esferas discursivas o los sistemas de comunicación.

Pero esa exigencia, cuyo objetivo es un concepto general de justicia, referente a todo y cualquier «discurso social» (TEUBNER, 1996a: 218), no basta para caracterizar la justicia como modelo normativo del tratamiento 
igual/desigual respecto de las esferas sistémicas y discursivas de una sociedad compleja. La justicia como igualdad compleja presupone la presencia de un sistema jurídico como mecanismo del tratamiento igual/desigual. La cuestión que se plantea, entonces, se relaciona con el tratamiento igual/desigual que se diversifica, adecuándose a la lógica de cada uno de los discursos o sistemas en que se diferencia la sociedad: «No es sólo: ¿trata el derecho lo igual igualmente y lo desigual desigualmente? Sino también: el derecho, al mismo tiempo, ¿es «justo» como el resto de discursos implicados en lo que la propia lógica les concierne?» (id., ibid.). En este sentido específico, la justicia como igualdad compleja reside en la pretensión normativa de que el derecho proceda a un tratamiento igual/desigual internamente consistente y que se adecue, en cada caso, a las exigencias de la esfera de comunicación expuesta a tal tratamiento mismo. El objetivo de la justicia, por tanto, es la construcción de modelos normativos que posibiliten la orientación de las decisiones jurídicas en sus propias consecuencias ${ }^{9}$, considerando la especificidad del respectivo discurso o sistema cuyo caso se presente al tratamiento igual/desigual. Ello implica la «re-entry» (SPENCER Brown, 1971: 56 s. u. 69 ss.) de elementos de otro sistema social en el derecho. Es decir, se impone una relectura de los criterios de otro sistema de conformidad con el código «lícito/ilícito» y con los criterios jurídicos del tratamiento igual/desigual.

Si un conflicto económico, por ejemplo, se convierte en un conflicto jurídico que exige un tratamiento justo, no basta con que el derecho recurra a las exigencias de la eficiencia económica, definida en primer lugar de acuerdo con el código tener/no-tener. Es necesario que se recurra a los programas del derecho, esto es a normas constitucionales, leyes, normas negociales y jurisprudencia, articulándolos en pos de un tratamiento igual/desigual de los agentes económicos que se trasformen en partes jurídicamente interesadas. Porque al convertirse el conflicto en un caso jurídico que exige un tratamiento justo, el principio económico de la eficiencia debe entonces ceder a los criterios jurídicos del tratamiento igual/desigual. Así es como un pequeño empresario, económicamente ineficiente, incluso insolvente, puede tener derecho y pretensión jurídica y salir victorioso en un proceso judicial contra una gran organización multinacional económicamente supereficiente. Pero en su decisión, el órgano competente, si se basa en el principio de la justicia como igualdad compleja, no puede actuar destructivamente respecto del propio principio de la eficiencia económica. La igualdad jurídica, aunque entre en constante conflicto con la eficiencia del sistema económi-

\footnotetext{
${ }^{9}$ Se discute, entonces, en qué medida y de qué modo las consecuencias de las decisiones pueden constituir fundamentos de derecho (TEUBNER [org.], 1995).
} 
co y deba combatirla cuando ésta se expande destructivamente contra los derechos, tiene que ser sensible a la lógica económica y afrontarla constructivamente para convertirse en una igualdad compleja. Esto significa que el tratamiento igual/desigual con respecto a un caso originariamente económico, para ser justo, es decir, para corresponder al principio de la igualdad compleja, precisa ser jurídicamente consistente y económicamente adecuado. En este sentido debe desecharse en la sociedad global compleja del presente no sólo la reducción de la justicia a un tratamiento igual/desigual insensible a sus consecuencias económicas, tal como propone tradicionalmente el formalismo jurídico. También es inadmisible cualquier reduccionismo de la justicia a una expresión jurídica de la eficiencia económica, tal como vienen proponiendo la escuela del llamado «Análisis Económico del Derecho» y el movimiento «law and economics» en los Estados Unidos de América. En el ámbito de esa corriente se desarrolla una concepción instrumental del derecho, de un derecho que en última instancia debe ser un instrumento de eficiencia económica. Así es como al admitir la posibilidad de diferentes interpretaciones de una misma ley el movimiento «law and economics prescribe que debe adoptarse la interpretación más adecuada para alcanzar la maximización de valor» (RosENFELD, 1998: 164). La racionalidad jurídica (tratamiento igual/desigual consistente y adecuadamente complejo) se subordinada a la racionalidad económica (maximización de valor), entendida como resultante de la «elección racional» ${ }^{10}$. Se da una especie de trivialización económica del derecho. En tal concepción subyace una visión simplista de la sociedad global compleja de hoy, que reduce la racionalidad social a la racionalidad económica. En realidad se parte de un dato empírico, el expansionismo del sistema económico con efectos destructivos sobre el resto de sistemas sociales, y se construye un modelo normativo de justicia. Mientras, la justicia como igualdad compleja, esto es, tratamiento igual/desigual sensible a la heterogeneidad de discursos y sistemas, implica entre otras cosas la exigencia de combatir el expansionismo de la economía, que desarrolla en detrimento de la autonomía del resto de esferas discursivas y sistémicas de la sociedad mundial.

Por tanto, no sólo con respecto a la economía, la justicia como igualdad compleja origina un tratamiento igual/desigual jurídicamente consistente y contextualmente adecuado. La justicia presupone la autonomía/identidad del derecho y, al mismo tiempo, la autonomía de cualquiera de sus contextos. La justicia no puede reducirse a los criterios de la ciencia, el arte, la educación, la religión, la política, la familia, etc. Se comprueba que en cier-

10 «El último Dios al cual el derecho debe sacrificarse hoy se llama rational choice» (Teubner, 1996a: 199). 
tas ocasiones más conocimientos científicos, promociones a artistas o a movimientos artísticos estéticamente más destacados, métodos de enseñanza que promuevan un mayor rendimiento del aprendizaje escolar, creencias religiosas profundas, decisiones políticas mayoritarias basadas en la discusión democrática e incluso el amor intenso en las relaciones familiares, acaban por transgredir los criterios del tratamiento igual/desigual jurídicamente consistente. Así pues, cuando los conflictos científicos, estéticos, educativos, religiosos, políticos y familiares se convierten en un conflicto jurídico y se exponen al tratamiento igual/desigual, los criterios de las respectivas esferas de comunicación no deben imponerse inmediatamente en el ámbito del derecho atentando contra la consistencia jurídica del tratamiento igual/desigual. Es imprescindible una relectura jurídica de los criterios del sistema a que originariamente pertenece el conflicto. Esto es, el tratamiento igual/desigual complejamente consistente exige la «reintroducción» («reentry») de esos criterios en el derecho. Pero desde la perspectiva de los contextos autónomos, el tratamiento igual/desigual debe ser sensible a las especificidades del respectivo sector de comunicación, es decir, según el caso, científica, artística, educativa, religiosa, política o familiarmente sensible. Se excluye así un formalismo jurídico insensible a la autonomía del contexto. Si el derecho actúa destructivamente con respecto a la autonomía de la ciencia, el arte, la educación, la religión, la política, la familia, etc., impidiendo que puedan reproducirse de acuerdo con sus propios códigos y criterios, entonces se vuelve incapaz de promover la justicia como igualdad compleja, a saber, de proceder a un tratamiento igual/desigual que se adecue a cada uno de esos sistemas sociales y, por ende, a la complejidad sistémica y a la heterogeneidad discursiva de la sociedad. En suma, la consistencia jurídica y la adecuación contextual del tratamiento igual/desigual son los dos aspectos indispensables de la justcia como igualdad compleja.

\section{V}

El modelo jurídico-político que ha resultado más satisfactorio para la promoción de la justicia como igualdad en la sociedad global compleja de hoy es el Estado democrático de derecho. Éste es el que dispone de los mecanismos y procedimientos más apropiados para el tratamiento igual/desigual jurídicamente consistente y socialmente adecuado a los diversos contextos.

Desde el punto de vista interno, el Estado democrático de derecho asegura tanto la autonomía operacional de la política como la del derecho. Al contrario que las formas autocráticas contemporáneas, que subordinan el derecho a la política, el Estado democrático implica una relación de horizontalidad e interdependencia entre esos dos sistemas de la sociedad global, 
en sus respectivas reproducciones en un territorio delimitado. Decisiva, a ese respecto, es la presencia de la Constitución como «acoplamiento estructural» entre derecho y política como sistemas sociales que se reproducen autónomamente (LuHMANN, 1990: 193 ss., 1993: esp. 470 ss., 1997: 782 s.). En este sentido, la Constitución «posibilita una solución jurídica del problema de autorreferencia del sistema político y, al mismo tiempo, una solución política del problema de autorreferencia del sistema jurídico» (LuHMANN, 1990: 202). La Constitución permite la «reintroducción» ("reentry") de lo jurídico en la política y de lo político en el derecho. Esto no significa la negación de la autonomía e identidad de los sistemas político y jurídico, sino la sensibilidad jurídica de la política y la sensibilidad política del derecho. El tratamiento igual/desigual, entonces, no se subordina inmediatamente a los criterios de la política, habiendo de ser jurídicamente consistente, sino que debe ser complejamente adecuado a las exigencias de la política democrática, para promover la justicia como igualdad compleja, que asume en tal caso la forma de justicia política. Así es como, basándose en la Constitución y mediante la jurisdicción constitucional, una decisión parlamentaria mayoritaria puede considerarse jurídicamente inválida, en especial cuando contradice los criterios jurídicos del tratamiento igual/desigual atentando de ese modo contra la justicia como igualdad.

A pesar de que tengan mayor relevancia en lo relativo a la relación del derecho con la política, pues el Estado democrático de derecho puede definirse como el modelo procedimental de la relación recíproca e intersección entre los sistemas jurídico y político, estas observaciones pueden extenderse a la relación del derecho con otras esferas de comunicación. A este respecto cabe considerar la Constitución desde el punto de vista específicamente jurídico. Por un lado, «la Constitución es la forma con la cual el sistema jurídico responde a su propia autonomía. La Constitución debe, en otras palabras, substituir soportes externos, tales como los que fueran postulados por el derecho natural» (LuHMANN, 1990: 187). En este sentido, Luhmann destaca que «la Constitución cierra el sistema jurídico, en cuanto lo regula como un dominio en el cual ella misma reaparece. Ésta constituye el sistema jurídico como sistema cerrado mediante la reintroducción en el sistema» (id., ibid.). De ello se desprende que los criterios de otros sistemas sociales no pueden obtener validez inmediata en el interior del sistema jurídico. La constitución establece una pluralidad de procedimientos -el jurisdiccional, el legislativo y el administrativo-burocrático-, por medio de los cuales las influencias y presiones externas sobre el derecho sufren una relectura de acuerdo con criterios específicamente jurídicos. Existe una especie de conmutación discursiva del lenguaje social del resto de diversas esferas de comunicación hacia un lenguaje específicamente jurídico, basán- 
dose todo ello en procedimientos constitucionales. Por añadidura, la Constitución del Estado democrático de derecho prevé el principio jurídico de isonomía, en el cual se basa el tratamiento igual/desigual y, por tanto, la justicia como igualdad compleja. La Constitución prevé asimismo los criterios normativos que posibilitan la realización práctica del principio de isonomía. Por consiguiente, las exigencias o conflictos científicos, económicos, artísticos, educativos, religiosos, familiares, etc. que se conviertan en exigencias o conflictos jurídicos, exponiéndose así al tratamiento igual/desigual, deben someterse procedimentalmente al principio constitucional de isonomía y a las normas constitucionales que constituyen sus criterios de concretización con el fin de que se haga así justicia como igualdad compleja.

Por otro lado, las normas constitucionales se refieren a las diversas esferas de comunicación en que se diferencia la sociedad, reconociendo y asegurando jurídicamente la autonomía de las mismas en el Estado democrático de derecho. Los propios derechos fundamentales pueden verse como una respuesta jurídico-constitucional a la diferenciación de la sociedad en diversos sistemas autónomos de comunicación (LuHMANN, 1986). El derecho responde a la autonomía de los sistemas sociales mediante la «reintroducción» («re-entry») de sus códigos-diferencia (tener/no tener, verdad/falsedad, transcendente/inmanente, etc.) y sus criterios en el propio derecho, que pasan de ese modo por una conmutación discursiva de acuerdo con el lenguaje jurídico. Así pues, la Constitución establece los derechos fundamentales de propiedad, libertad contractual, libertad de elección de trabajo, respondiendo de ese modo a las exigencias de un sistema económico autónomo, así como prescribe la liberdad científica, religiosa y artística, la libertad de enseñar y aprender, el acceso a la educación, la protección a la familia y la elección democrática, respondiendo de ese modo a las respectivas exigencias de desarrollo autónomo de la ciencia, la religión, el arte, la educación, la familia y la política. Esto significa que cuando las exigencias o conflictos de esas esferas diferenciadas de comunicación se convierten en exigencias o conflictos jurídicos y se exponen, por tanto, al tratamiento igual/desigual en los términos del principio constitucional de isonomía, el derecho no debe imponer sus criterios indistintamente a cualquiera de esas esferas ignorando sus especificidades y, por tanto, dañándolas o destruyendo su autonomía. Amén de jurídicamente consistente, el tratamiento igual/desigual en el Estado democrático de derecho tiene que adecuarse a las exigencias específicas de las diversas esferas sistémicas y discursivas de la sociedad. Se impone que, guiados por el principio de isonomía, los procedimientos constitucionales sean sensibles, según el caso, a la economía, la ciencia, la religión, el arte, la educación, la familia y la política, adecuando el tratamiento igual/desigual a cada una de esas esferas de comuni- 
cación. Sólo así esas esferas pueden promover la justicia como igualdad compleja. Sería absurdo y profundamente injusto en la sociedad global supercompleja de hoy pretender, en nombre del principio jurídico de isonomía, prohibir toda y cualquier desigualdad económica, impedir la desigualdad en el conocimiento científico, las diferencias, desigualdades o carencia de fe religiosa y de aptitud artística, la desigualdad en la capacidad de enseñar y de aprender, negar la asimetría de poder entre minoría y mayoría parlamentaria, entre gobierno y oposición, así como pretender abolir la patria potestad ignorando la diferencia entre padres e hijos. Pese a ello no debe olvidarse, sin embargo, que la autonomía de las diversas esferas de comunicación implica el acceso universal a las mismas. La justicia como igualdad compleja también es, por consiguiente, incompatible con la «exclusión» de personas y grupos de la economía, la educación, la política y cualquier otro sistema social. La justicia conlleva una relectura de la exigencia de «inclusión social» como «inclusión jurídica» en términos de derechos fundamentales de acceso a las diversas esferas diferenciadas y autónomas de comunicación. En suma, si la justicia como igualdad compleja, que ha de realizarse en los diversos procedimientos constitucionales del Estado democrático de derecho, tiene que adecuarse a la especificidad y a la autonomía/identidad de las diferentes esferas discursivas o sistémicas de la sociedad global de hoy, debe no sólo compatibilizarse con la forma singular de libertad imprescindible para cada una de ellas, sino también con la «inclusión» universal como exigencia específica de cada subsistema social.

Pero la comprensión del Estado democrático de derecho como modelo jurídico-político más satisfactorio para la justicia como igualdad compleja no se desprende sólo de un análisis sistémico de la autorreferencia y heterorreferencia del derecho. Se debe observar también cómo a partir de una esfera pública pluralista caracterizada por la heterogeneidad de valores, intereses y discursos, los procedimientos del Estado democrático de derecho se legitiman (heterolegitimación) y sirven para la promoción de la justicia como igualdad. Defino esfera pública como campo de tensión entre la Constitución en cuanto acoplamiento estructural entre política y derecho, por un lado, y por otro el mundo de la vida, en cuanto espacio social no estructurado sistémicamente, y resto de sistemas funcionales de la sociedad. La esfera pública es la consecuencia de aquellas espectativas, valores, intereses y discursos que, por destacarse de los sistemas funcionalmente diferenciados de la sociedad y perder así su sentido sistémico específico, o que por provenir del mundo de la vida, aspira a generalizarse política y jurídicamente a través de los procedimientos constitucionales. La esfera pública es la arena de la disensión. Se trata de una disensión estructural entorno a valores, intereses, expectativas normativas y discursos. Los procedimientos 
del Estado democrático de derecho no se legitiman en cuanto pretenden negar esa disensión o buscar un consenso entorno a esos valores, intereses, expectativas y discursos. Éstos no están destinados, desde un punto de vista normativo incluso, a la búsqueda del consenso, tal como propone la teoría habermasiana del discurso -fundada en la teoría de la acción comunicativa como acción orientada al entendimiento intersubjetivo- dentro su concepción del Estado democrático de derecho (HABERMAS, 1992). La legitimación que proviene de la esfera pública no es fruto del consenso entorno al resultado de los procedimientos, ya sea tal consenso supuesto, fáctico o hipotético-racional. Lo esencial es que los procedimientos constitucionales, independientemente de sus resultados, permanezcan abiertos a la diversidad de expectativas, valores e intereses, incluso los eventualmente descartados. Los procedimientos actúan selectivamente, pero no tendrían fuerza legitimadora si ignorasen la continuidad de la disensión en la esfera pública. Los canales de mutación deben permanecer abiertos al flujo de informaciones de carácter contradictorio y conflictivo que llega del mundo de la vida y de los diversos sistemas sociales autónomos. No se excluyen nuevas posibilidades de vigencia normativa y decisión vinculante. En este sentido, lo que se impone (deber ser) para la manutención de una esfera pública pluralista es el consenso entorno a los procedimientos constitucionales. Así pues, la observancia de estos procedimientos no sólo legitima el resultado procedimental en el interior de los sistemas jurídico y político reestructurando expectativas (LuHMAnN, 1983: esp. 119 e 252 s.), sino que también legitima el sistema constitucional como un todo desde la perspectiva externa de la esfera pública, independientemente del resultado eventual del procedimiento. Es decir, el Estado democrático de derecho se legitima en cuanto sus procedimientos absorben sistémicamente la disensión y, al mismo tiempo, posibilitan, median e incluso fomentan la emergencia de la misma en la esfera pública. Como modelo jurídico-político, el Estado democrático de derecho se legitima en cuanto es capaz de mediar el consenso procedimental y la disensión de contenido y, de ese modo, posibilitar y promover el respeto a las diferencias en la sociedad global supercompleja contemporánea.

Desde el punto de vista específico de la justicia como igualdad compleja, eso significa que el tratamiento igual/desigual exige procedimientos constitucionales abiertos a la disensión estructural de la esfera pública. Los resultados de los procedimientos no pueden constituirse en forma de exclusión de otras posibilidades de tratamiento igual/desigual. La incertidumbre del derecho, que se relaciona con la complejidad de la sociedad y la heterogeneidad estructural de la esfera pública, implica incluso la posibilidad de diferentes concretizaciones correctas del principio de isonomía: una interpretación jurídicamente consistente y socialmente adecuada de tal principio 
puede entrar en conflicto con otras alternativas de tratamiento igual/desigual que también sea jurídicamente consistente y socialmente adecuado. La justicia como igualdad se hallará definitivamente maltrecha si pretende negar la incertidumbre en cuanto a la interpretación y concretización del principio constitucional de isonomía, reprimiendo de ese modo la complejidad sistémica de la sociedad y la disensión estructural de la esfera pública. La justicia como igualdad que el Estado democrático de derecho ha de realizar es incompatible, por tanto, con un fundamentalismo jurídico respecto del principio constitucional de isonomía. Al contrario, la justicia implica el reconocimiento, la absorción y la viabilización procedimental de la disensión entorno al tratamiento igual/desigual, una disensión que en la sociedad global supercompleja de hoy resulta de la diferencia de posturas valorativas, la diversidad de modelos discursivos, la variedad de intereses y la congruencia de perspectivas sistémicas respecto del principio constitucional de isonomía.

\section{VI}

Aunque sea plausible la afirmación de que el Estado democrático de derecho se ha presentado como el modelo jurídico-político más satisfactorio para la realización de la justicia como igualdad en la sociedad compleja de hoy, se puede observar que bajo la presión tanto de la llamada «globalización económica» como de los conflictos étnicos y de los fundamentalismo religiosos, en las últimas décadas dicho Estado ha perdido en eficiencia y capacidad de integración.

Como consecuencia de la globalización económica, entendida aquí como expansionismo del sistema económico con efectos destructivos para la reproducción autónoma de otras esferas de comunicación, se amplían las formas económicamente determinadas de «exclusión» social en el sentido amplio del término, es decir, por un lado, falta de acceso a los beneficios y ventajas de los diversos sistemas sociales vinculada a la dependencia de sus reglas y restricciones (subintegración), y por otro, acceso a los primeros independientemente de estas últimas (sobreintegración) (NEVES, 1994, 1992: 94 ss. e 155 ss. $)^{11}$. El problema deja de ser una singularidad de los llamados

${ }^{11}$ En la utilización de los conceptos de subintegración y sobreintegración me acompaña Müller, 1997: 47 ss., esp. 49 ss. Cf. también O’Donnell, 1999: 312 y 332, nota 47. Desde una perspectiva distinta, partiendo primeramente de la dependencia (deberes, responsabilidades, etc.) y no del acceso (derechos, acciones, etc.) como los dos aspectos del concepto de inclusión, Luhmann afirma más tarde, enfrentándose a mi formulación conceptual anterior, que el «sector de exclusión» [Inklusionsbereich] está superintegrado (porque es más dependiente), en cuanto la inclusión permite una menor integración (LUHMANN, 1993: 584 s., 1995: 259 s., 1997: 631 s.). Mientras, tal como formulo, subintegración y sobreintegración implican una in- 
«países periféricos», donde el Estado democrático de derecho, en rigor, nunca se realizó de manera satisfactoria, y se extiende a los «países centrales», en especial a aquéllos de América del Norte y de la Europa Occidental desarrollada, donde el modelo de Estado democrático de derecho como Estado de bienestar tiene un éxito considerable. En este sentido cabe hablar incluso de tendencia a una «periferización del centro» (NEVES, 1998: 153 ss.). Problemas sociales típicos que se relacionan con la «exclusión» social tienden a expandirse a escala global, de tal modo que incluso la concepción de la primacía de la diferenciación funcional en la sociedad mundial se torna cuestionable.

La intolerancia étnica, no sólo en la forma escandalosa que tomó por ejemplo en los Balcanes y África, donde destruyó o impidió la propia existencia del Estado, sino también en la forma del neonazismo o neofascismo que se intensifica en Europa Occidental, principalmente como reacción ante los nuevos flujos de inmigración que huyen de la «exlusión» en sus países de origen, y los fundamentalismos religiosos constituyen igualmente fenómenos que recientemente vienen amenazando cada vez más el Estado democrático de derecho. Los conflictos étnicos y religiosos que se derivan de ello, al contrario que los conflictos de intereses, no son susceptibles de mediación (LuHMANN, 1998: 372). Los grupos étnicamente intolerantes o religiosamente fundamentalistas rechazan los procedimientos del Estado democrático de derecho, precisamente porque éstos reconocen la disensión estructural de la esfera pública procurando absorberla, mediarla, posibilitarla o incluso fomentar su emergencia. Mediante la intolerancia étnica y el fundamentalismo religioso, se pretende negar la diversidad étnica de valores, así como la autonomía de las esferas discursivas y sistémicas, reaccionando destructivamente frente a la heterogeneidad cultural y la complejidad sistémica de la sociedad global del presente, heterogeneidad y complejidad a las que el Estado democrático de derecho procura, mediante un consenso procedimental y una disensión de contenido, dar una respuesta jurídico-política adecuada.

Evidentemente, el expansionismo del código económico y la «exclusión» social por un lado, y la intolerancia étnica y los fundamentalismos religiosos por otro, son incompatibles con la justicia como igualdad compleja. El primero implica la negación de la autonomía de las diversas esferas discursivas y sistémicas, presupuesto y exigencia de la justicia como igualdad compleja. La «exlusión» social es incompatible con el universalismo de

clusión insuficiente (y, por tanto, una exclusión parcial), ya sea por falta de acceso o de dependencia, respectivamente. Ello explica porque tanto los subciudadanos como el sobreciudadano carecen de ciudadanía en cuanto mecanismo de inclusión político-jurídica en la sociedad. 
la justicia en la medida en que implica la discriminación negativa de una gran parte de la población (subintegración) y los privilegios de una minoría (sobreintegración). La intolerancia étnica y el fundamentalismo religioso, a su vez, rechazan la diferencia y, por tanto, la relatividad inherente al universalismo de la justicia en la sociedad global compleja del presente. En ésta, la justicia presupone y exige la autonomía de las diversas esferas de comunicación, la «inclusión» social generalizada y el respeto a las diferencias de valores-identidad y de valores-preferencia.

Como reacción a la reciente crisis del Estado democrático de derecho en Europa Occidental y América del Norte, relacionada con la llamada «globalización» económica y con las nuevas formas de intolerancia étnica y fundamentalismo religioso, fenómenos que se agravan tras la caída de los regímenes pretendidamente socialistas de Europa del Este, se tiende a la búsqueda de nuevos procedimientos e instituciones que puedan servir de alternativas a la incapacidad regulatoria y la deficiencia del Estado, principalmente en lo relativo a la realización de la justicia como igualdad compleja. En este particular destacan dos tendencias: una apela a los órdenes jurídicos globales, plurales y heterárquicos (TEUBNER, 1996b, 1996c); la otra, a una «política interna mundial» [Weltinnenpolitik] supraordenada al Estado (HABERMAS, 1998a, 1998b, 1999a, 1999b, 1996: esp. 128 ss. y 217 ss.). Ambas son susceptibles de restricciones (cf. Neves, 1998: 153 ss.), especialmente en lo relativo a la realización de la justicia como igualdad compleja a escala mundial.

El énfasis de Teubner en los órdenes jurídicos globales y plurales (law's global villages), cada uno de ellos acoplado estructuralmente con uno de los sistemas mundiales -economía, ciencia, turismo, transporte, etc.- es sin duda seductor. Pero en la propia concepción posmoderna de Teubner ya se pueden percibir síntomas de los límites del pluralismo jurídico global. Cabe observar que Teubner concentra su enfonque en el derecho económico mundial, específicamente en la lex mercatoria, el único ejemplo de law's global village que analiza (1996b: 264 ss.); en el tratamiento de esta forma de derecho mundial se pone de relieve una falta de autonomía de la lex mercatoria frente a los procesos económicos globales subrayándose que ésta es extremamente vulnerable a las presiones y ataques de los actores económicos y, en este sentido, también en el futuro seguirá siendo «un derecho corrupto» (id., ibid.: 279). Por tanto, en rigor, tal orden jurídico global, la lex mercatoria, constituye el instrumento de la economía mundial y tiene por función servir a ese sistema. En otras palabras, constituye el derecho al servicio del dinero. Por consiguiente, no se trata de una forma de derecho que pueda servir para la justicia como igualdad compleja, la cual presupone un derecho autónomo frente al sistema económico. Subordinada a la economía 
global y trivializada por ésta, la lex mercatoria como derecho económico global no es el orden jurídico apropiado para promover un tratamiento igual/desigual que amén de económicamente adecuado sea jurídicamente consistente. Es apto para proceder a una estabilización jurídica del juego económico, pero no para producir justicia como igualdad compleja.

Habermas, al contrario que Teubner, defiende una solución política unitaria que se presenta en forma de «proyecto» de «política interna mundial», que distinguiéndose de un Estado mundial sea capaz de hallar las instituciones y los procedimientos necesarios para la construcción de intereses comunes en términos de una ciudadanía mundial (HABERMAS, 1998a: 79 s.). Tal «proyecto» tiene dos problemas en perspectiva: la crisis del Estado de bienestar frente a la sobrecarga de una economía gobalizada (1998a, 1998b: 79 ss.); la violación flagrante y escandalosa de los derechos humanos en amplias regiones del globo terrestre (1999a, 1999b, 1998b: 170 ss.). Con respecto al primer caso, Habermas propone «la transferencia hacia instancias supranacionales de funciones que, aun ahora, los Estados sociales tengan asumidas en el ámbito nacional» (1998a: 75 o 1998b: 86.) y de ese modo la «construcción de un régimen global de bienestar» (1998a: 80). Respecto al segundo, se manifiesta favorable a la llamada «intervención humanitaria» y propone que la misma se legitime mediante la institucionalización de procedimientos jurídicos en el plano de las organizaciones internacionales.

Este no es el lugar para profundizar en el análisis del proyecto habermasiano, inigualablemente seductor (a este respecto, véase NEVES, 1998: 153 ss.). Me limitaré a algunas observaciones generales. Con respecto a la idea de un «régimen general de bienestar», Habermas no extrae las debidas consecuencias del hecho, por él reconocido, de que el Estado social sólo puede desarrollarse «en algunas regiones privilegiadas, en las condiciones favorables de la posguerra» y que la «interdependencia asimétrica entre los países desarrollados, los industrializados recientemente y los subdesarrollados» permanece intocable (HABERMAS, 1998a: 76 o 1998b: 87). La orientación incluyente en el Estado de bienestar del Occidente desarrollado no surgió sin una amplia exclusión en otras regiones del globo terrestre. En la actualidad vuelve a darse la tendencia de que olas de exclusión, dentro del contexto de la globalización económica, se extiendan en los países centrales. Frente a la gran desigualdad económica entre Norte y Sur y frente a una sociedad global fuertemente conflictiva, me parece que la noción de un «régimen global de bienestar» y la idea de la necesidad de una «solidaridad cosmopolita» (1998a: 77 o 1998b: 88) con vistas a una «ciudadanía mundial» desempeñan más bien un papel ideológico y no contribuyen adecuadamente a la construcción de mecanismos consecuentes de solución de los graves problemas sociales de la sociedad global compleja de hoy. Lo que se 
observa, en realidad, son reacciones supranacionales a escala regional, como por ejemplo la Unión Europea, que en lugar de una política de bienestar global solidaria tiende a reaccionar drásticamente ante la ola migratoria de los «fugitivos de la exclusión», emigrantes de otras regiones del planeta. Se trata, por tanto, de una política interna de bienestar del Occidente desarrollado que no sirve para la justicia como igualdad compleja a escala global y que implica incluso formas de tratamiento injusto contra los inmigrantes. En cuanto a la llamada «intervención humanitaria» se puede afirmar que ésta, sobre todo en virtud de la estructura no democrática del Consejo de Seguridad de la ONU, que «realiza un intervencionismo arbitrario» con respecto a los derechos humanos (BRUNKHORST, 1999: 382), de las «intenciones paternalistas» inherentes a las propuestas interventivas y de la clasificación «selectiva» de las violaciones de los derechos humanos que dan lugar a la intervención (MAUS, 1997: 168 e 190), no constituye en rigor una «política interna mundial» democráticamente institucionalizada para la implantación de los derechos humanos, sino más bien una política externa del Occidente desarrollado oligárquicamente estructurada para la vigilancia de las políticas de «derechos humanos» de los países más frágiles en la constelación del poder internacional. Así pues, no se trata de una institución de la justicia como igualdad compleja, sino de un instrumento de poder internacional.

Por tanto, el Estado democrático de derecho sigue siendo el que, para el combate de la injusticia estructural de la sociedad global compleja del presente, sociedad caracterizada por amplias formas de «exclusión» social e intolerancia para con lo diferente, mediando un consenso procedimental y una disensión de contenido, ofrece el modelo jurídico-político más adecuado. Evidentemente, el éxito y la difusión de ese modelo dependen de políticas consecuentes de seguridad, derechos humanos, medioambientales y de desarrollo en el ámbito de las organizaciones internacionales, así como de reglas eficientes de estabilización de las relaciones económicas globales, principalmente en lo relativo al mercado financiero. Y, para la innovación y adecuación a las nuevas redes de comunicación de la sociedad mundial, el Estado democrático de derecho ha de abrirse a las provocaciones e irritaciones de la pluralidad de los órdenes jurídicos globales. Por añadidura, no debe ignorarse que a causa de las inmensas desigualdades sociales entre individuos y grupos, que implican la «exclusión» de amplias partes de la población del planeta, y de las enormes asimetrías de desarrollo entre regiones y países, las perspectivas de difusión del Estado democrático de derecho a escala mundial son muy negativas. Por ello existe a largo plazo la necesidad de profundas transformaciones en el grado de desarrollo y las relaciones económicas internacionales, sumamente conflictivas, no habiendo en 
el momento actual perspectivas en el sentido de tales transformaciones. Ello, sin embargo, no debe ocultar el hecho de que el Estado democrático de derecho aún constituye el modelo jurídico-político que, capaz de adecuarse a los más diferentes contextos (multi-)culturales y las más diversas exigencias regionales, puede promover más satisfactoriamente la justicia como igualdad compleja. Esta justicia, en caso de no contar con los procedimientos efectivos del Estado democrático de derecho, estará abocada en la sociedad global compleja del presente a reducirse a un tópico de retórica política, en especial de aquella retórica política vinculada a la etiqueta de «globalización», en cuyo ámbito el mercado se celebra como criterio último de la justicia.

(Traducción de Ángel Espinosa Gadea)

\section{Bibliografía}

ARISTÓTELES (1941): Ethica Nicomachea (Nicomachean Ethics), trad. ingl. de W. D. Ross, in: Richard McKeon (org.), The Basic Works of Aristotle, New York: Random House, pp. 927-1112.

Bandeira de Mello, Celso Antônio (1993): Conteúdo Jurídico do Princípio da Igualdade, 3. ${ }^{\text {a }}$ ed., São Paulo: Malheiros.

BRUNKHORST, Hauke (1999): «Heterarchie und Demokratie», in: BRUNKHORST, Hauke / Niesen, Peter (orgs.), Das Recht der Republik, Frankfurt am Main: Suhrkamp, pp. 373-385.

Comparato, Fábio Konder (1993): «Igualdade, Desigualdades», in: Revista Trimestral de Direito Público, 1/1993 (São Paulo: Malheiros), pp. 69-78.

Dworkin, Ronald (1991a): Taking Rights Seriously, 6. ${ }^{\mathrm{a}}$ ed., London: Duckworth (1. ${ }^{\mathrm{a}}$ ed.: 1977).

Dworkin, Ronald (1991b): Law's Empire, London: Fontana Press (1. a ed.: 1986).

GidDEns, Anthony (1991): The Consequences of Modernity, Cambridge: Polity Press.

HABERMAS, Jürgen (1992): Faktizität und Geltung: Beiträge zur Diskurstheorie des Rechts und des demokratischen Rechtsstaats, Frankfurt am Main: Suhrkamp.

- (1996): Die Einbeziehung des Anderen: Studien zur politischen Theorie, Frankfurt am Main: Suhrkamp.

- (1998a): «Jenseits des Nationalstaats? Bemerkungen zu Folgeproblemen der wirtschaftlichen Globalisierung», in: BECK, Ulrich (org.), Politik der Globalisierung, Frankfurt am Main: Suhrkamp, pp. 67-84.

- (1998b): Die postnationale Konstellation: Politische Essays, Frankfurt am Main: Suhrkamp.

- (1999a): «Zur Legitimation durch Menschenrechte», in: BRUNKHORST, Hauke / NieSEn, Peter (orgs.), Das Recht der Republik, Frankfurt am Main: Suhrkamp, pp. 386-403.

- (1999b): «Bestialität und Humanität: Ein Krieg an der Grenze zwischen Recht und Moral», in: Die Zeit, 29. April 1999, pp. 1, 6 e 7. 
HonNeth, Axel (1995): «Einleitung», in: idem (org.), Kommunitarismus: Eine Debatte über die moralischen Grundlagen moderner Gesellschaften, 3. ${ }^{\mathrm{a}}$ ed., Frankfurt am Main / New York: Campus, pp. 7-17.

Jouvenel, Bertrand de (1976): Les Débuts de l'État Moderne: Une histoire des idées politiques au XIX ${ }^{e}$ siècle, Paris: Fayard.

Trad. bras. (1978): As origens do Estado Moderno: Uma história das idéias políticas no século XIX, Rio de Janeiro: Zahar.

Kelsen, Hans (1960). Reine Rechtslehre, 2. ${ }^{\mathrm{a}}$ ed., Wien: Franz Deuticke (reimpresión inalterada: 1983).

LuHMann, Niklas (1981): Ausdifferenzierung des Rechts, Frankfurt am Main: Suhrkamp.

- (1983): Legitimation durch Verfahren, Frankfurt am Main: Suhrkamp.

- (1986): Grundrechte als Institution: Ein Beitrag zur politischen Soziologie, 3. ${ }^{\mathrm{a}}$ ed., Berlin: Duncker \& Humblot.

- (1987a): Rechtssoziologie, 3. ${ }^{\mathrm{a}}$ ed., Opladen: Westdeutscher Verlag.

- (1987b): Soziale Systeme: Grundriß einer allgemeinen Theorie, Frankfurt am Main: Suhrkamp.

- (1988): «Positivität als Selbstbestimmtheit des Rechts», in: Rechtstheorie 19 (Berlin: Duncker \& Humblot), pp. 11-27.

- (1989): Vertrauen: Ein Mechanismus der Reduktion sozialer Komplexität, 3. ${ }^{\mathrm{a}}$ ed., Stuttgart: Enke.

- (1990): «Verfassung als evolutionäre Errungenschaft», in: Rechtshistorisches Journal 9 (Frankfurt am Main: Löwenklau), pp. 176-220.

- (1991): «Der Gleichheitssatz als Form und als Norm», in: Archiv für Rechts- und Sozialphilosophie 77 (Stuttgart: Steiner), pp. 435-445.

- (1993): Das Recht der Gesellschaft, Frankfurt am Main: Suhrkamp.

- (1995): «Inklusion und Exklusion», in: idem, Soziologische Aufklärung 6: Die Soziologie und der Mensch, Opladen: Westdeutscher Verlag, pp. 237-264.

- (1997): Die Gesellschaft der Gesellschaft, Frankfurt am Main: Suhrkamp, 2 tomos.

- (1998): «Der Staat des politischen Systems: Geschichte und Stellung in der Weltgesellschaft», in: BECK, Ulrich (org.), Perspektiven der Weltgesellschaft, Frankfurt am Main: Suhrkamp, pp. 345-380.

Luhmann, Niklas / De Giorgi; Raffaele (1992): Teoria della società, Milano: Franco Angeli.

MAUS, Ingeborg (1997): «Staatssouveränität als Volkssouveränität. Überlegungen zum Friedensprojekt Immanuel Kants», in: Wilfried Loth (org.), Jahrbuch 1996 des Kulturwissenschaftlichen Instituts im Wissensschaftszentrum NRW, Essen: Altes Rathaus, pp. 167-194.

MoRIN, Edgar (1990): Introduction à la pensée complexe, Paris: ESF.

MülLER, Friedrich (1997): Wer ist das Volk? Die Grundfrage der Demokratie - Elemente einer Verfassungstheorie VI, Berlin: Duncker \& Humblot.

NeVES, Marcelo (1992): Verfassung und Positivität des Rechts in der peripheren Moderne: Eine theoretische Betrachtung und eine Interpretation des Falls Brasilien, Berlin: Duncker \& Humblot.

- (1994) «Entre Subintegração e Sobreintegração: A Cidadania Inexistente», in: DADOS - Revista de Ciências Sociais 37/2 (Rio de Janeiro: IUPERJ), pp. 253276. 
- (1998): Symbolische Konstitutionalisierung, Berlin: Duncker \& Humblot.

O'Donnell, Gillermo (1999): «Polyarchies and the (Un)Rule of Law in Latin America: A Partial Conclusion», in: MÉNDEZ, Juan E. / O'DonNELL, Gillermo / PINHEIRO, Paulo Sérgio (orgs.), The Un(Rule) of Law and the Underprivileged in Latin America, Notre Dame, Indiana: University of Notre Dame Press, pp. 303-337.

RAWLS, John (1990): A Theory of Justice, Oxford: Oxford University Press (1. a ed.: 1972).

RoberTson, Roland (1992): Globalization: Social Theory and Global Culture, London: Sage.

Rosenfeld, Michel (1998): Just Interpretations: Law between Ethics and Politics, Berkeley / Los Angeles / London: University of California Press.

SANDEL, Michael J. (1982): Liberalism and the limits of Justice, Cambridge: Cambridge University Press.

Spencer Brown, G. (1971): Laws of Form, London: George Allen and Unwin (Reimpressão da 1. ${ }^{\mathrm{a}}$ ed. de 1969).

TAYLOR, Charles (1991): «Cross-Purposes: The Liberal-Communitarian Debate», in: Rosenblum, Nancy L. (org.), Liberalism and the Moral Life, Cambridge, Mass. / London: Harvard University Press, pp. 159-182.

TeUbNER, Gunther (org.) (1995): Entscheidungsfolgen als Rechtsgründe: Folgenorientiertes Argumentieren in rechtsvergleichender Sicht, Baden-Baden: Nomos.

Teubner, Gunther (1996a): «Altera Pars Audiatur: Das Recht in der Kollision anderer Universalitätsansprüche», in: Archiv für Rechts- und Sozialphilosophie, Beiheft 65 (Wiesbaden: Steiner), pp. 199-220.

- (1996b): «Globale Bukowina: Zur Emergenz eines transnationalen Rechtspluralismus», in: Rechtshistorisches Journal 15 (Frankfurt am Main: Löwenklau), pp. 255-290.

- (1996c): «Des Königs viele Leiber: Die Selbstdekonstruktion der Hierarchie des Rechts», in: Soziale Systeme: Zeitschrift für soziologische Theorie 2 (Opladen: Leske + Budrich), pp. 229-255.

- (1998): «Nach der Privatisierung? Diskurskonflikte im Privatrecht», in: Zeitschrift für Rechtssoziologie 19 (Wiesbaden: Westdeutscher Verlag), pp. 8-36.

Tocqueville, Alexis de (1986): De la Démocratie en Amérique, vol. I, Paris: Gallimard.

Touraine, Alain (1994): Qu'est-ce que la démocratie?, Paris: Fayard.

- (1997): Pourrons-nous vivre ensemble? Égaux et différents, Paris: Fayard.

WALZER, Michael (1983): Spheres of Justice: A Defense of Pluralism and Equality, New York: Basic Books.

- (1994): Thick and Thin: Moral Argument at Home and Abroad, Notre Dame I London: University of Notre Dame Press.

- (1998): «Vorwort zur deutschen Ausgabe», trad. alemana de Claus Offe, in: WALzER, Michael, Sphären der Gerechtigkeit: Ein Plädoyer für Pluralität und Gleichheit, Frankfurt am Main: Fischer, pp. 11-14.

WeLSCH, Wolfgang (1991): «Gesellschaft ohne Meta-Erzählung?», in: ZAPF, Wolfgang (org.), Die Modernisierung moderner Gesellschaften: Verhandlungen des 25. Deutschen Soziologentages in Frankfurt am Main 1990, Frankfurt am Main / New York: Campus, pp. 174-184. 
$\triangle \quad$ DOXA 24 (2001) 